\title{
Chapter 15 \\ Cyclical Parthenogenesis in Daphnia: Sexual Versus Asexual Reproduction
}

\author{
Ellen Decaestecker, Luc De Meester and Joachim Mergeay
}

\begin{abstract}
In the current chapter, we discuss the peculiar but successful reproduction mode of cyclical parthenogenesis, using the cladoceran genus Daphnia as a model. We first focus on the cyclically parthenogenetic life cycle of Daphnia, the phylogenetic backgrounds of this reproduction mode, and how cyclical parthenogenesis impacts the genetic structure of Daphnia populations. Further, we discuss the advantages of sex. Finally, we change perspective and discuss evolution from cyclical parthenogenesis to strict asexuality in this genus, contrasting the advantages and drawbacks of both strategies, starting from the selective environment of obligate asexuals.
\end{abstract}

\subsection{Introduction}

Most animal taxa use sexual reproduction to produce offspring, while a minority passes on their genes asexually. Both strategies have their advantages and weaknesses, and throughout evolution, a number of taxa have evolved independently a mixed strategy that seems to combine the best of both worlds: phases of asexual propagation are alternated with bouts of sexual reproduction, called cyclical parthenogenesis, holocycly or heterogony. Cladocerans, monogonont rotifers (see Chapter 14) and aphids (see Chapter 25) are the best-known cyclical parthenogens, but life cycles combining sexual and asexual reproduction are common in protists, cnidarians, bryozoans, and plants (De Meester et al. 2004). We here focus on recent studies and reviews of cyclical parthenogenesis in Daphnia so as to identify future avenues of research. Detailed reviews that also include older literature are given by Hebert (1978, 1987), Lynch (1984), Carvalho (1994) and De Meester (1996).

\footnotetext{
E. Decaestecker $(\bowtie)$

Laboratory of Aquatic Ecology and Evolutionary Biology, K.U. Leuven, Ch. Debériotstraat 32, B-3000 Leuven, Belgium; Laboratory of Aquatic Biology, Interdisciplinary Research Center, K.U. Leuven Campus Kortrijk, E. Sabbelaan 53, B-8500 Kortrijk, Belgium e-mail: Ellen.Decaestecker@kuleuven-kortrijk.be
} 
De Meester et al. (2004) focused on key ecological and evolutionary consequences of cyclical parthenogenesis, comparing cladocerans, monogonont rotifers and aphids.

\subsection{Cyclical Parthenogenesis and Its Effect on the Genetic Structure of Daphnia Populations}

Cyclical parthenogenesis arose within the Branchiopoda during the Permian (Taylor et al. 1999) when the Cladocera evolved as a taxon. Apart from a few strictly asexual derivates, all Cladocera are cyclical parthenogens. The success of this reproduction mode is reflected in the known 620 species that radiated within this order, this is more than half of the known Branchiopod species diversity and the estimated number of cladoceran species is even two to four times higher (Korovchinsky 1996; Adamowicz and Purvis 2005; Forró et al. 2008). Cladocera are ubiquitous components of inland aqueous habitats all around the world, but are rare in marine habitats. Within the Cladocera, the genus Daphnia, approximately 150 species rich, has been used as a key model to study ecological and evolutionary questions, including the consequences of cyclical parthenogenesis.

Daphnia (Crustacea, Branchiopoda, Cladocera, Daphniidae) is an important component of zooplankton in lakes and ponds. It has a short generation time (911 days at $20^{\circ} \mathrm{C}$ ), but total life span is longer ( $>60$ days at $20^{\circ} \mathrm{C}$, up to one year at colder temperatures; Gliwicz et al. 2001). Figure 15.1 shows the reproduction cycle of cyclically parthenogenetic Daphnia. Under favourable conditions, they reproduce by amictic parthenogenesis, producing genetically identical offspring that build up a population consisting of only females. This can be continued for several generations, resulting in an exponential growth of clonal lineages (Carvalho 1994). The

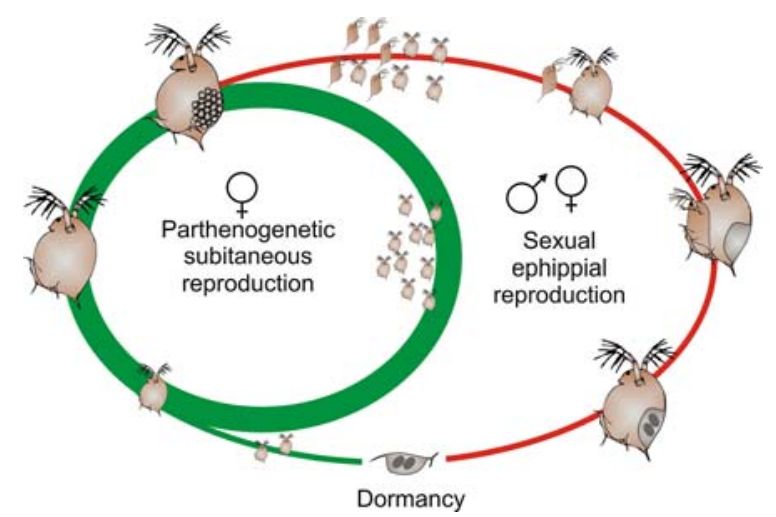

Fig. 15.1 The cyclically parthenogenetic life cycle of Daphnia. During favourable conditions, parthenogenetic reproduction takes place for one to several generations (green). Sexual reproduction $(r e d)$ results in the production of long-lived dormant eggs, which can hatch once environmental conditions become favourable again. Some taxa have omitted males from the cycle and produce dormant eggs asexually 
relative abundance of these clones reflects their relative success in the habitat. When unfavourable conditions arise (e.g., food shortage, overcrowding, presence of predators, change in day-length or temperature, Pijanowska and Stolpe 1996), the animals switch to sexual reproduction. Males are produced parthenogenetically, and females switch to the production of sexual eggs. A single female may first produce diploid amictic eggs and subsequently produce two meiotic haploid eggs that need to be fertilized (De Meester et al. 2004). After fertilization of the haploid eggs, they are encapsulated in an ephippium, a chitinuous membrane secreted around the brood pouch of the female carapace (Schultz 1977). Development of the eggs is arrested at the blastula stage, and the eggs go in diapause. At the next moult, the ephippium is shed with the old carapace (Zaffagnini 1987). The enclosed dormant eggs are able to withstand extreme conditions (drying, freezing, digestion, ...) and can remain viable for up to 150 years (Cáceres 1998; Brendonck and De Meester 2003).

Dormancy is therefore a strategy to bridge unfavourable periods (risk spreading over time), while also maximizing the chances of survival during passive dispersal by wind, waterfowl or other means (risk spreading in space, Cohen and Levin 1987). The dormant eggs may hatch the next season when favourable conditions are restored, but a significant portion will not hatch and remain in the sediment. As such, a series of overlapping generations gradually builds up year after year, in what is commonly called a persistent dormant egg bank (DeStasio 1989), analogous to seed banks in plants (Templeton and Levin 1979). Depending on prevailing selection forces, these dormant egg pools can accelerate or delay evolutionary responses to changing environments (Hairston and DeStasio 1988; Hedrick 1995; Hairston 1996). In addition to the evolutionary and ecological importance of the presence of a dormant egg bank in the stratified sediments of lakes and ponds, it also represents a unique archive of the history of the population over time (Hairston et al. 1999; Cousyn et al. 2001; Limburg and Weider 2002; Mergeay et al. 2006, 2007).

The genetic structure of cyclically parthenogenetic Daphnia populations is determined by the consequences of combining sexual and asexual reproduction in the same life cycle (Hebert 1987; Carvalho 1994; De Meester et al. 2006). At the start of the growing season, hatching of sexually produced dormant eggs introduces genetic variation in the population, with a one-to-one relationship between the number of hatchlings and the number of unique clones (De Meester 1996; De Meester et al. 2006). However, during the growing season, parthenogenetic reproduction results in the erosion of clonal diversity by natural selection and chance extinctions of clones, leading to lower genetic variation and deviations from HardyWeinberg equilibrium at the end of the growing season (clonal erosion, Tessier et al. 1992; De Meester 1996; Ortells et al. 2006; De Meester et al. 2006). The population may, however, hold considerable amounts of hidden genetic variation that is not genetically expressed as long as the animals reproduce clonally, but which may become expressed after sexual recombination (Deng and Lynch 1996; Pfrender and Lynch 2000). Natural selection acts differently during the two reproductive phases (Pfrender and Lynch 2000; King and Schonfeld 2001). During the asexual phase, all genes belong essentially to one linkage group, and selection thus acts upon the whole linked genome. As a result, clonal selection also acts on the interaction of 
genetic variation. In contrast, sexual reproduction breaks up the associations of these linked alleles.

De Meester et al. (2006) recently proposed a unifying conceptual framework to understand the genetic structure of cyclically parthenogenetic zooplankton populations. In this framework, the key factor that influences the genetic structure of cyclical parthenogens is the relative importance of sexual recombination and parthenogenetic reproduction. De Meester et al. (2006) list three main factors that determine the degree to which clonal erosion affects the genetic structure of cyclical parthenogens. A first factor is the population size as determined by the amount of hatchlings from the dormant egg bank. Populations that have larger dormant egg banks are expected to start the growing season with a higher number of hatchlings and thus a higher number of clones than populations with smaller dormant egg banks (Vanoverbeke and De Meester 1997). A second factor is the length of the growing season and the degree to which a population can persist in the habitat in the active phase, as this determines the number of parthenogenetic generations between sexual phases (Hebert 1987; Pfrender and Lynch 2000). Permanent populations and non-permanent populations that enjoy extended growing seasons show higher propensities of chance extinctions of clones and experience longer lasting selection that erodes clonal diversity. Furthermore, the impact of hatchlings in spring is likely to be lower in permanent than in intermittent populations, as the presence of a resident population often lowers the hatching response in Daphnia (Cáceres and Tessier 2003) and the hatchlings have to compete with the already established population (cf. priority effects; see De Meester et al. 2002). A third factor influencing the degree of clonal erosion is the strength of clonal selection, which may vary among populations and during the course of the growing season (De Meester et al. 2006).

\subsection{Reasons to Maintain Sexual Reproduction in Daphnia}

Sexual reproduction has costs relative to asexual reproduction (Lewis 1987), yet, sexual reproduction prevails in nature. A main reason for the maintenance of sexual reproduction is the improvement of fitness, despite the reduction in overall number of offspring ("two-fold" cost of sexual reproduction, Maynard Smith 1978). Many hypotheses focus on this issue, building on the notion that sexual recombination accelerates the creation of genetic variation in offspring by the induction of new gene combinations, the spread of advantageous mutations, and the removal of deleterious genes. As such, sexual reproduction leads to higher rates of adaptation and inhibits the accumulation of deleterious mutations (West et al. 1999; Pound et al. 2002; see also Chapter 5).

\subsubsection{Local Genetic Adaptation}

Cyclical parthenogenesis allows for rapid local genetic adaptation, as it combines effective selection on the whole genetic component of variation during the parthenogenetic phase with the release of hidden genetic variation during sexual 
recombination (Lynch and Gabriel 1983; De Meester 1996). Evolutionary potential is increased by the fact that sexual reproduction is coupled with the production of dormant eggs, as this results in the build-up of dormant egg banks integrating genetic variation that accumulates over different growing seasons (Hedrick 1995). One can thus predict that cyclical parthenogens are likely to adapt rapidly to local conditions through selection for genotypes with an adaptive combination of phenotypic plasticity responses (De Meester et al. 2004). Several studies have indeed provided evidence for efficient tracking of environmental changes over time in natural Daphnia populations (e.g., Hairston et al. 1999, 2001; Cousyn et al. 2001). Striking examples of adaptation through changes in phenotypic plasticity in Daphnia come from studies that show genetic differences in adaptive and inducible shifts in trait values in response to predators, including behavioural, morphological and life history traits (Spitze 1992; De Meester 1993a, 1996; Boersma et al. 1998; Tollrian and Harvell 1999; Cousyn et al. 2001). Adaptations to local conditions may, however, involve complex interactions between multiple antagonists, such as predators and parasites, leading to trade-offs between different response mechanisms (Decaestecker et al. 2002).

\subsubsection{Red Queen Dynamics}

When an environment changes, previously neutral or deleterious alleles can become favourable. If the environment changes sufficiently rapidly over time (i.e., between different generations), sexual reproduction reintroducing these alleles can be advantageous. This is especially so in systems in which parasites continuously track specific and common host genotypes, resulting in parasite driven time-lagged negative frequency dependent selection. The production of genetic variation among offspring provided by sexual recombination is thus important in confrontation with the fast and specific genetic adaptation of parasites to their hosts ("Red Queen" hypothesis, Van Valen 1973; Hamilton 1980; Stearns 1987; Maynard Smith 1989; Ebert and Hamilton 1996; Hurst and Peck 1996; see also Chapter 7).

In Daphnia, it has been shown that parasites are important selective forces. Many natural populations are infected by parasites, some of which induce severe virulence effects, resulting in fitness decline in the host (Green 1974; Stirnadel and Ebert 1997; Decaestecker et al. 2005; Ebert 2005; Johnson et al. 2006; Lass and Ebert 2006). Furthermore, there is evidence for local genetic adaptation of the parasite along spatial distance gradients (Ebert 1994) as well as for short-term parasite mediated selection in Daphnia (Capaul and Ebert 2003; Haag and Ebert 2004; Duncan et al. 2006; Zbinden et al. 2008), which affects host-parasite dynamics (Duffy and Sivars-Becker 2007). It has also been shown that parasite epidemics can select for resistance in Daphnia (Duncan and Little 2007).

Several lines of evidence suggest that Daphnia-parasite coevolution follows "Red Queen" dynamics with no directional increase in fitness of both antagonists over time (Hamilton et al. 1990; Woolhouse et al. 2002; Ebert 2008). It has been shown that there is ample genetic variation in Daphnia resistance against parasites (Little 
and Ebert 1999). Host clones within and between populations vary strongly in their resistance to parasites, but also parasites differ strongly in fitness components between host genotypes and populations (Carius et al. 2001; Decaestecker et al. 2003; Haag et al. 2003; Refardt and Ebert 2007; Ebert 2008). Host-parasite interactions are genotype-specific with no parasite isolates being able to infect all host genotypes, and no host genotypes that are able to resist all parasite genotypes (Carius et al. 2001). It has also been shown in the D. galeata x D. hyalina hybrid system that an under-infected taxon can become over-infected after an increase in frequency, and that this over-infection has a genetic basis (Wolinska et al. 2006).

The observation that both Daphnia and its microparasites can be "resurrected" from dormant propagule banks opened the possibility for a historical reconstruction of the coevolutionary dynamics of Daphnia and its parasite Pasteuria ramosa from layered sediment cores (Decaestecker et al. 2004). A time shift experiment, in which host clones from each sediment layer were exposed to parasite isolates from the same, the previous and the following sediment layer showed evidence for temporal adaptation with the contemporary parasites showing a higher infectivity than parasite isolates from the past and the future, resulting in temporal variation in parasite infectivity that changed little over time. This analysis revealed that the parasite fast tracks its host over a time period of only a few years, in line with specific antagonistic host-parasite coevolution based on negative frequency dependent selection (Decaestecker et al. 2007; Gandon et al. 2008; Ebert 2008).

Little and Ebert (2001) found in one of the studied host populations temporal adaptation to parasites showing higher infectivity in Daphnia from the same growing season than in hosts of a later growing season. However, this pattern could not be confirmed in other populations. The expected pattern of host-parasite coevolution depends, among other things, on the time lag between the host and parasite coevolutionary dynamics, on the time scale separating the various samples of the host populations and on the number of generations of hosts and parasites considered (Decaestecker et al. 2007; Gandon et al. 2008). Moreover, it has been suggested that parasite selection must be unrealistically severe to create rapid parasite mediated dynamics or that genotype-environment interactions impede detection of selection against environmental noise (Little and Ebert 2001; Duncan et al. 2006). Seasonal changes in temperature and predation alter the interaction between Daphnia and parasites such that differences in temperature and predation pressure will change parasite mediated selection, resulting in the maintenance of genetic variation of the traits involved (Mitchell et al. 2004, 2005; Duffy et al. 2005; Hall et al. 2006; Vale et al. 2008).

However, sex and immuno-competence do not necessarily go hand in hand, for example, when sexual reproduction is a byproduct of temporal parasite-avoidance (Duncan et al. 2006), in a similar way that sexual reproduction can be induced when Daphnia are confronted with predators (Sluzarczýk 1995). In such cases, the main goal of sexual reproduction is not genetic recombination in order to increase immuno-competence, as the sexual phase precedes parasitism (Duncan et al. 2006), but the formation of dormant stages to ensure persistence in the habitat. 


\subsubsection{Deleterious Mutations}

Sexual reproduction can reduce the mutational load in offspring, as it enhances the removal of deleterious mutations. Sexual reproduction allows to reconstruct mutation-free individuals by recombination and by doing so inhibits the random loss of individuals without deleterious mutations. It was Muller (1932), who suggested that this stochastic process can lead to an inexorable decline in the fitness of clones in finite asexual populations ("Muller's ratchet"; Muller 1932; Felsenstein 1974; see also Chapter 5). In later studies, Muller's basic idea was extended by including cases in which mutation accumulation is decoupled from stochastic processes, such that an advantage to sex can accrue even in infinite populations ("Mutational Deterministic" hypothesis, Kondrashov 1982, 1988; Charlesworth 1990; Howard and Lively 1998). As selection against mutations of weak to intermediate deleterious effect is small, these mutations can accumulate to high frequencies (Whitlock et al. 2000; Ebert et al. 2002). There is evidence for high genetic loads in Daphnia (Innes 1989; De Meester 1993b; Lynch and Deng 1994). Further, Paland and Lynch (2006) showed that, because of permanent linkage of the whole genome, asexual $D$. pulex clones may be prone to the accumulation of deleterious mutations, leading to a higher ratio of the rate of amino acid to silent substitution $\left(\mathrm{K}_{\mathrm{a}} / \mathrm{K}_{\mathrm{s}}\right)$ in mitochondrial protein coding genes in asexual lineages than in cyclically parthenogenetic ("sexual") lineages. This result suggests that sexual reproduction in the cyclically parthenogenetic Daphnia has the power to indeed reduce the accumulation of deleterious mutations, and obligately parthenogenetic Daphnia face a decline in fitness over time. Nevertheless, there are indictations that sufficient amounts of variation (relative to mutation rate) are generated in Daphnia by ameiotic recombination. Although this recombination is internal and does not allow genetic exchange across lineages as in outcrossing sex, it shows that asexual lineages do not only acquire variation through mutations (Omilian et al. 2006).

Evidence is growing that a pluralistic approach may be required to explain the maintenance of sexual reproduction (West et al. 1999). Support for this approach in Daphnia comes from an experimental study, in which fitness consequences of deleterious mutations were stronger when associated with parasite infection (Killick et al. 2006). As shown for parasite mediated selection in Daphnia (Mitchell et al. 2005; Vale et al. 2008), the fitness cost of deleterious mutations depends on environmental conditions as well (Killick et al. 2006).

Another explanation for the advantage of sexual reproduction in Daphnia may relate to the direct advantage caused by hybrid vigour or heterosis. Inbreeding depression has consequences at the Daphnia metapopulation level, as shown by Ebert et al. (2002) and Haag et al. (2002). In a Daphnia metapopulation inhabiting small coastal rockpools in Finland, crossing between immigrants and inbred residents leads to hybrid offspring that are superior competitors. This increases gene flow between populations and the spread of favourable alleles across the metapopulation (Ebert et al. 2002; Haag et al. 2002). 


\subsection{Evolution to Asexuality in Daphnia and Other Cladocerans}

Although cyclical parthenogenesis is the rule in Cladocera (Taylor et al. 1999), a few taxa have modified this life cycle, and have shunted away from sexual reproduction, while retaining the possibility to produce resistant dormant stages. For instance, asexuality has been observed in allopolyploid lineages of Sinobosmina (Little et al. 1997), while an asexual or possibly pseudo-sexual life cycle was suggested for several Holopedium lineages (Korovchinsky 2005; Hebert et al. 2007). Within the genus Daphnia, evolution to obligate asexuality has evolved in at least four independent occasions by to three different mechanisms (Table 15.1).

In the animal kingdom, hybridization is probably one of the most used routes to asexuality, often in combination with genome duplication (allopolyploidy) (Kearney 2005). Obligate parthenogenesis of hybrid origin in Daphnia is known from the subgenera Daphniopsis (D. truncata x pusilla; Hebert and Wilson 2000), Ctenodaphnia (allopolyploid alpine populations of D. thomsoni; Hebert and Wilson 1994) and in various related species of the subgenus Daphnia (D. pulex complex; Hebert et al. 1989; Dufresne and Hebert 1994, 1997; Hebert 1995; Aguilera et al. 2007; Mergeay et al. 2008).

Apart from obligate parthenogenesis through hybridisation with or without polyploidy, asexuality has been acquired de novo in some populations of $D$. cephalata (Hebert 1981; Hebert and Wilson 1994), an Australian species of the D. carinata complex (Colbourne et al. 2006).

Thirdly, in certain lineages of panarctic D. "pulex" (a different species from the typical European D. pulex; see Mergeay et al. 2008, for an account on taxonomic issues in this group) females reproduce by obligate parthenogenesis, whereas the clonally propagated males produce functional haploid sperm that allows them to breed with sexual females of normal cyclically parthenogenetic lineages (contagious asexuality; Innes and Hebert 1988; Paland et al. 2005). On average half of the offspring will also consist of obligate parthenogens, although offspring viability is much reduced (Innes and Hebert 1988). Paradoxically, contagiously asexual lineages thus spread asexuality through sex. The genetic structure of contagiously asexual populations is undistinguishable from that of strictly asexual lineages. Although asexual lineages are bound to accumulate deleterious mutations (Paland and Lynch 2006) and face an evolutionary dead end, contagious asexuality allows the recurrent creation of genetically diverse asexual lineages with lower genetic loads and high micro-evolutionary potential (Innes and Hebert 1988; Simon et al. 2003). This interaction between asexual and sexual strains means that the maternal lineage actually partially escapes Muller's ratchet by creating new asexual lineages that carry half of its genes and have a reduced mutational load. As long as the cyclically parthenogenetic sister taxon is present, there is an opportunity to continuously rejuvenate part of the genome. Metapopulations of contagiously asexual lineages can thus be expected to be genetically diverse (Innes and Hebert 1988; Crease et al. 1989). Remarkably, however, there seems to be a certain degree of 


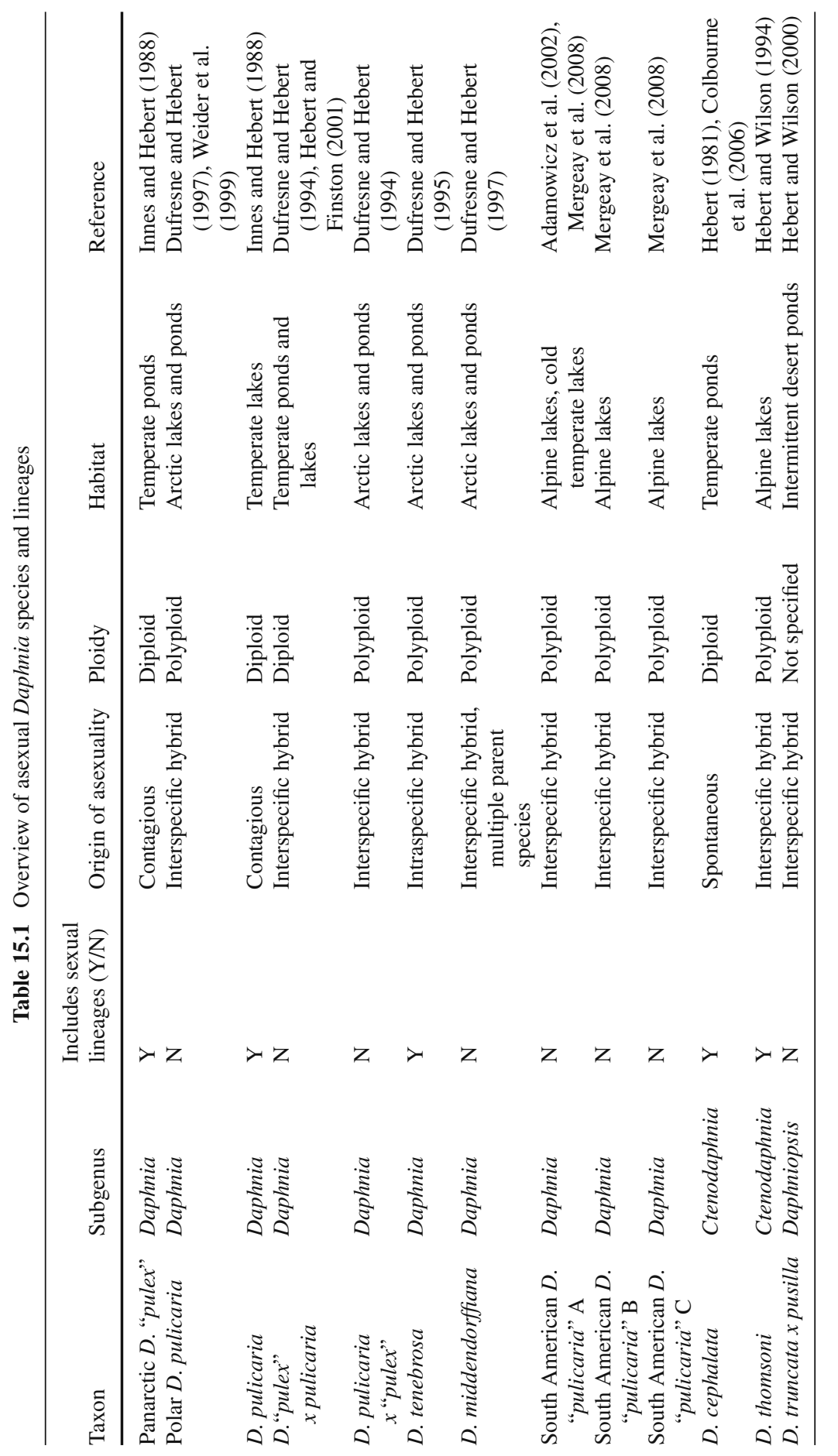


longitudinal geographic segregation between cyclically parthenogenetic and contagiously asexual lineages of $D$. "pulex" in North America, with few and relatively narrow contact zones (Hebert and Finston 2001). Most likely, asexuality in contagiously asexual lineages is determined by a sex-limited meiosis suppressor gene that is thought to have spread to at least some other species in the complex by hybridisation and introgression (Innes and Hebert 1988). Eight of eleven taxa of the D. pulex complex are known to include lineages that reproduce by obligate parthenogenesis (Table 15.1), but many of these are hybrids and even polyploids. It is therefore not clear whether the same meiosis suppressor mechanism is active in these lineages, or whether asexuality results directly from hybridization and meiotic incompatibility between the parents (for an overview, see Simon et al. 2003).

In addition to these three cases of asexuality, which are characterised by the disruption or suppression of meiosis at some stage ("fundamental asexuality"), there are Daphnia populations that are theoretically cyclically parthenogenetic, but whose genetic structure is undistinguishable from that of obligately parthenogenetic populations. These populations remain all year round in the lakes they inhabit, and seem to use solely the parthenogenetic phase of the life cycle (Fig. 15.1). An example is given by a $D$. galeata population studied by Gliwicz et al. (2001; identified as $D$. longispina) and several D. pulicaria populations studied by Cáceres and Tessier (2004a). Such populations can easily be mistaken for strictly asexual lineages, and care should be taken in the interpretation of their breeding modes. First, it is not certain whether these lineages have really lost the capacity to engage in sexual reproduction, and secondly, it is even not sure whether occasional sexual reproduction is not occurring in nature in these populations. Indeed, lack of observation of sexual stages does not preclude the very rare occurrence of sex. A special case of lineages that may totally rely on asexual reproduction is provided by hybrid offspring of members of the $D$. longispina complex that live in permanent habitats such as deep lakes. This complex includes species whose ancestors diverged more than eight million years ago, but which still hybridise readily, e.g., D. galeata, D. cucullata, D. longispina. (Schwenk and Spaak 1995). Although their hybrids have a strongly reduced fertility, they can survive and reproduce parthenogenetically for long periods and may in this sense behave as asexual strains that have lost the ability to produce viable dormant eggs (Schwenk and Spaak 1995).

\subsection{Why Switch to Asexual Reproduction When You Can Be a Cyclical Parthenogen?}

A large number of hypotheses have been proposed to explain the evolution of sex and later reversals to asexuality, accompanied by numerous empirical and theoretical studies (Maynard Smith 1971, 1978; Vrijenhoek 1979; Kondrashov 1988; Crow 1994; Peck 1994; Doncaster et al. 2000; Peck and Waxman 2000; Pound et al. 2002, 2004; Paland and Lynch 2006). Most of these hypotheses have focused on the cost 
of males, effects of sex on the mutational load or on the rate of evolutionary adaptation, or on ecological differences between sexual organisms and asexual derivates. To cut a long story short, it is the balance between the costs and the benefits of sex that determines whether sexual reproduction is more advantageous than asexual reproduction.

Cyclical parthenogens generally start the growing season from sexual offspring, and hence can start from a wide genetic array on which selection can act, just like in obligately sexual organisms with a r-strategy of reproduction. In comparison to obligately sexual organisms, however, this initial pool of sexually produced offspring will grow much faster as a result of consecutive bouts of parthenogenetic reproduction. Males are produced only during the much shorter sexual phase (Fig. 15.1), and will therefore represent an almost negligible cost, especially when seen in the light of the benefit of recombination. Moreover, clonal selection is efficient during the parthenogenetic phase as it acts on both the interactive and the additive component of genetic variation. Evolutionary adaptation can indeed proceed very rapidly in cyclical parthenogens, as witnessed by Hairston et al. (1999), Cousyn et al. (2001) and Decaestecker et al. (2007). In addition, cyclical parthenogens have a much higher mutational clearance than asexual relatives (Paland and Lynch 2006). Cyclical parthenogenesis thus seems to combine all the advantages of sex, while minimizing the drawbacks. In this light, the high prevalence and multiple origins of asexuality, as in the $D$. pulex complex, is intriguing. To gain more insights into the origin of obligate asexuality from cyclical parthenogenesis, we consider what the drawbacks of the cyclically parthenogenetic reproduction mode are. Below, we discuss existing hypotheses in the light of cyclical parthenogenesis, as well as integrating new concepts that might provide better insights into the evolution of asexuality in lineages of cyclical parthenogens. The first hypothesis is related to the timing of sexual reproduction, the second and third relate to constraints imposed by time stress during the growing season, and the fourth hypothesis is unrelated to time, but sees obligate parthenogenesis as a side-product of selection for polyploidy and/or hybrid vigour. Finally, we explore contagious asexuality in the light of selfish gene phenomena.

\subsubsection{Clonal Erosion and Inbreeding}

Probably one of the major assets of cyclical parthenogenesis is that it initially mimics an asexual life cycle for a number of generations before switching to a sexual mode. The timing of the switch is important, however. Clonal selection erodes the initial genetic diversity during the parthenogenetic phase, and in small and permanent habitats this may lead to the coexistence of only a very limited number of clones (Vanoverbeke and De Meester 1997; De Meester and Vanoverbeke 1999; De Meester et al. 2006). If only one to a few genotypes remain due to clonal erosion, sexual reproduction is disadvantageous as it results in inbreeding and concomitant fitness losses (De Meester 1993b; Lynch and Deng 1994; Ebert et al. 2002). Asexual genotypes do not suffer from inbreeding, and can be favoured over sexual lineages 
under such circumstances. In addition to time, habitat heterogeneity may also influence the degree of clonal erosion. The more clones can coexist in a given habitat, the less important inbreeding will be. Whereas the tangled bank hypothesis (Bell 1982) views sexual recombination as an adaptation to environmental diversity, we here suggest that environmental diversity may also result in reduced levels of inbreeding depression in cyclical parthenogenesiss as it allows more clones to coexist, reducing the scope for asexual lineages to dominate because of inbreeding depression in sexual offspring. The high prevalence of asexual Daphnia at high latitudes and altitudes (geographic parthenogenesis; see also Chapter 7), is associated with low habitat complexity, which is a typical feature of extreme environments like arctic ponds (disclimax habitats, Glesener and Tilman 1978).

\subsubsection{Food Limitations and Time Stress}

In the cyclical parthenogenetic life cycle, the first clutch usually consists of subitaneous parthenogenetic eggs, and it is important to note that most species can only produce dormant eggs from the second clutch, either sexually or ameiotically. (Only two species are known to produce ephippial eggs in a single cycle; Cáceres and Tessier 2004b; Aguilera et al. 2007). In extremely oligotrophic habitats, growth rates of Daphnia are so low that the whole growing season may be needed to reach maturity, which is the case in some alpine lakes (Gliwicz et al. 2001). Daphnia may suffer from the same stress in very ephemeral or other briefly suitable habitats. If time and food constraints are such that reproducing at least twice (once parthenogenetically, once sexually) becomes unlikely, immediate investment in dormant eggs may be a strategy to ensure persistence. So far, only one sexual species is known to bypass this limitation. D. ephemeralis is a cold stenotherm pond species that hatches earlier than any other species, but is rapidly outcompeted by $D$. pulex when temperatures rise in spring (Schwartz and Hebert 1987; Cáceres and Tessier 2004b). Hatchlings from dormant eggs of this species can consist of parthenogenetic females as well as sexual females and males (Schwartz and Hebert 1987). D. ephemeralis can thus reduce the cyclically parthenogenetic cycle to an entirely sexual cycle, in which the animals immediately invest in the production of sexual dormant eggs. However, this strategy of rapid investment in dormant eggs is easier to accomplish in obligately parthenogenetic species, where no males are needed to fertilize the eggs. Indeed, Spanish Pyrenees populations of $D$. pulicaria and Andean populations of an undescribed D. pulex-like species (Pérez-Martínez et al. 2007; Aguilera et al. 2007; Mergeay et al. 2008) are obligate asexuals that can produce ephippial dormant eggs from the first clutch. Although both strategies are similar and the reproductive output is low (only two eggs can be produced per ephippium), sexual species also suffer from the twofold cost of males (Maynard Smith 1978). In general, the cost of males in cyclically parthenogenetic Daphnia is highly diluted when many parthenogenetic generations precede the sexual generation. However, when the parthenogenetic phase is strongly reduced or even absent, cyclical parthenogenesis may become less advantageous than obligate parthenogenesis. 


\subsubsection{Genetic Slippage and Time Stress}

Although sexual reproduction allows more rapid evolution than asexual reproduction, sexual reproduction can be disadvantageous as it disassembles previously successful gene combinations due to genetic recombination during meiosis (Allen and Lynch 2008). Especially in cyclical parthenogens, where clonal selection during the preceding phase of parthenogenetic reproduction also selects on genetic interaction effects, the result is that the initial average fitness of the sexual offspring (F1) is lower than that of the parents (F0), a phenomenon known as genetic slippage (Fig. 15.2a; Lynch and Deng 1994; Deng and Lynch 1996; Allen and Lynch 2008). During the growing season, however, clonal selection will lead to a re-increase of the average fitness up to or exceeding that of the previous generation (Fig. 15.3). Although in sexual lineages genetic slippage will be less pronounced the shorter the growing season is, the increase in average fitness will also be smaller due to a shorter period of clonal selection. In asexual populations, all else being equal, the fitness of F0 and F1 would remain the same (Fig. 15.2b). In very predictable, but time-stressed

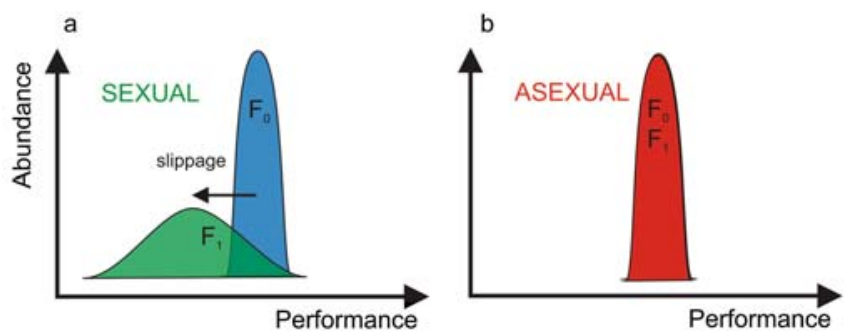

Fig. 15.2 Genetic slippage in sexual organisms as compared to amictic parthenogenetic organisms. F0: parental generation; F1: offspring generation

Fig. 15.3 The effect of clonal selection on average fitness in sexual populations after genetic slippage, shown at ten time intervals ( $\mathrm{t} 0-\mathrm{t} 9)$. $\mathrm{F} 0$ represents the parental generation (blue), while F1 represents the offspring (green). Under time stress, the final average fitness is lower than when time stress is relaxed

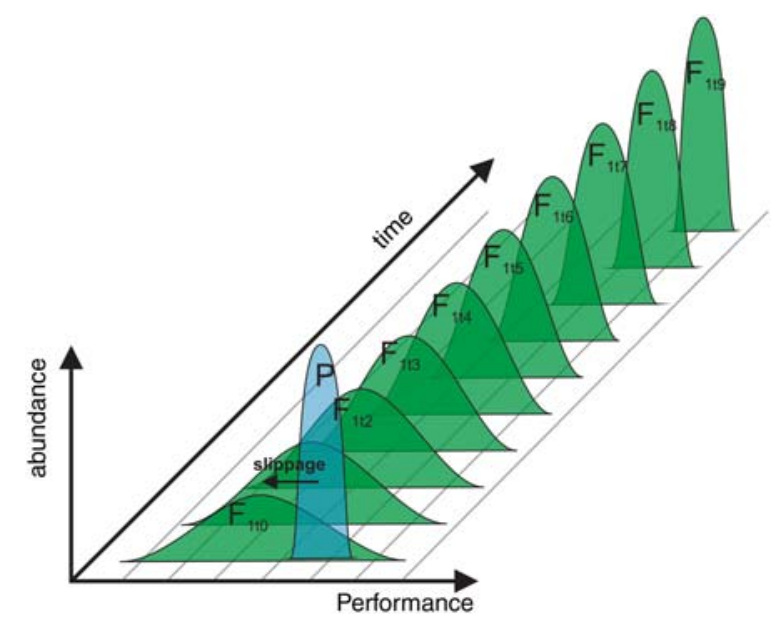



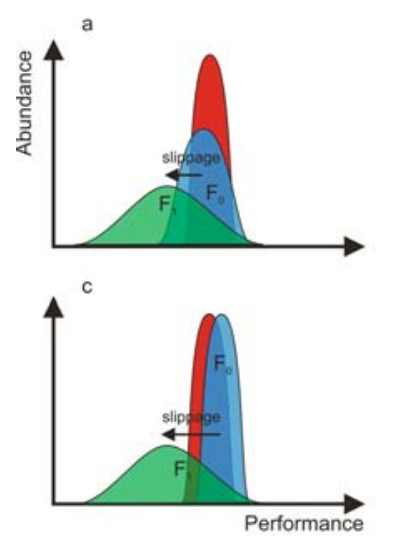
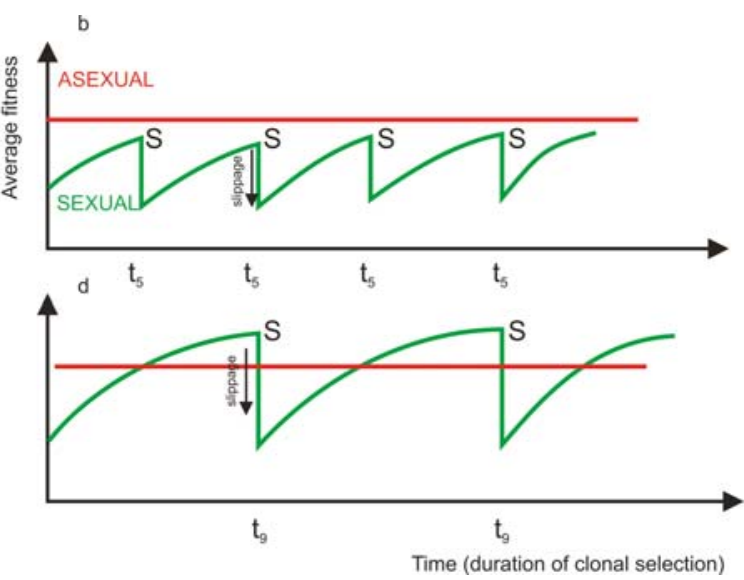

Fig. 15.4 The effect of time stress and genetic slippage on average fitness of a population at the time of sexual reproduction ( $\mathrm{S}$ ). $\mathbf{a}+\mathbf{b}$ : Under time stress ( $\mathrm{S}$ at $\mathrm{t5}$ ), clonal selection may not be strong enough to purge the population from less fit genotypes, so that the average fitness remains well below the maximum achievable average fitness of a population that has abandoned sexual reproduction. $\mathbf{c}+\mathbf{d}$ : When time stress is relaxed ( $\mathrm{S}$ at t9) and clonal selection can act long enough, the average fitness of sexual populations can exceed that of asexuals. t5 and 19 refer to equal time intervals as in Fig. 15.3

habitats (habitats in which the ambient conditions for growth and development are short and which are thus characterized by a short growing season), asexuals may take advantage of such a temporal sex-related fitness reduction (Fig. 15.4a, b). Asexuals would be able to start the growing season with a population consisting entirely of equally well-adapted individuals, while sexual populations start with an on average lower fitness but also with greater variance in fitness over all individuals. Although the increased genetic variation on which subsequent clonal selection can act may compensate for this reduced fitness, this requires time for clonal selection to purge the population from the less fit genotypes (Fig. 15.4c, d). In combination with slow growth rates (e.g., in oligotrophic arctic or alpine systems), the advantage of asexuality could therefore be quite high (Fig. 15.4a, b), at least in habitats that show a similar selection regime over time (e.g., from year to year). Arctic or alpine ponds and lakes are harsh but relatively predictable habitats, in which co-adapted gene complexes are important to cope with the harsh conditions, but in which the uncertainties introduced by biotic interactions are relatively low.

Genetic surveys of asexual Daphnia in the arctic have shown that in several species a few common asexual genotypes have very wide geographic distributions, spanning over a thousand kilometres (Weider et al. 1999). These common clones may either be general-purpose genotypes (Lynch 1984; Weider et al. 1999) or their widespread distribution might merely reflect the presence of a common habitat type over large distances combined with an efficient screening of the best adapted genotype to that habitat (itself being a combination of high dispersal rates and local selection; see De Meester et al. 2002). 


\subsubsection{Polyploidy and Hybrid Vigour}

Polyploidy, hybridization and asexuality are three phenomena that are firmly entwined with each other. Cause and effect are therefore often hard to distinguish (Simon et al. 2003; Kearney 2005). Most asexual Daphnia lineages are polyploids of hybrid origin (Table 15.1), as most other secondary asexual organisms (Kearney 2005). It is thought that polyploidy and the associated genetic redundancy represent an adaptation to increased mutagenic stress (Zakharov et al. 1970). It is thus conceivable that polyploidy and associated loss of sexual recombination have an adaptive value at high altitudes and latitudes. Asexuality in arctic or alpine regions may therefore to a certain degree be an epiphenomenon of selection for hybrid vigour (Kearney 2005) and/or polyploidy (Beaton and Hebert 1988). Circumstantial data support this hypothesis, by showing that polyploids occur more in UV radiation-stressed environments like alpine and boreal regions (Bierzychudek 1985). More specifically, within the D. pulex complex, only polyploid Daphnia are found in arctic settings (Beaton and Hebert 1988). The high incidence of cuticular melanisation in Daphnia from arctic or alpine regions (Hebert 1995; Černý and Hebert 1999) is indeed in line with the idea that UV radiation is an important stressor in these habitats. In addition, polyploidy seems to be adaptive at low temperatures. There is evidence that greater cell volumes, achieved through polyploidy, are favoured in arctic and alpine habitats (Otto and Whitton 2000), but diploid Daphnia can also achieve this through endopolyploidy (Gregory and Hebert 1999). Dufresne and Hebert (1998) showed that polyploid strains of D. middendorffiana performed better under cold conditions than diploid strains of the sister taxon $D$. pulex. Although their results were not phylogenetically independent and may just reflect species-specific differences not related to ploidy level, they fit the general trend of polyploidy as an adaptation to cold temperature stress. A similar example of geographic polyploidy accompanied by asexuality is found in alpine New Zealand populations of $D$. thomsoni, a species of the $D$. carinata complex (Hebert and Wilson 1994).

\subsubsection{Contagious Asexuality: Selfish or Not?}

One may argue that contagious asexuality is not an adaptive strategy per se, because it may merely be a selfish gene phenomenon, and that the question of the reason behind an asexual reproduction mode may thus be irrelevant. However, for a selfish gene, the meiosis suppressor allele may not be very efficient, as on average only one third of the offspring of contagiously asexual males and cyclically parthenogenetic females are viable (Innes and Hebert 1988). As a result, there seems to be an important net cost of male investment (see also Innes et al. 2000), as the fitness of males will on average be only one sixth of the fitness of obligately parthenogenetic females (one obligately parthenogenetic female that produces two dormant eggs has a maximal fitness of two, whereas three contagiously asexual males are 
needed to contribute to the equivalent of one viable egg). The maintenance of contagious asexuality is therefore more likely to be found in the advantages of occasional recombination (cf. supra) than that it represents a selfish gene phenomenon.

\subsection{Conclusions}

We provided an overview of possible scenarios for the evolution of asexuality in Daphnia that mostly involves either a contagious spread of a meiosis suppressor gene or hybridisation. Intriguingly, this genus shows a wide range of degrees of asexuality, from entirely sexual $D$. ephemeralis over normal cyclically parthenogenetic lineages that end every growing season with a bout of sexual recombination to effectively asexual populations of facultatively sexual species, contagiously obligate parthenogens that occasionally engage in sexual reproduction through their males, and strictly asexual lineages. Although asexuality is most abundant in Daphnia in the D. pulex species complex, the common incidence of this reproduction mode within this group and their wide geographic distribution reflects the success of this reproductive strategy under specific environmental conditions.

Acknowledgements We thank J. Vanoverbeke and D.J. Innes for comments on an earlier version of the manuscript. This project was supported by the K.U. Leuven Research Fund (projects OT/04/23, CREA/08/009 and STRT1/08/019) and by the ESF EURODIVERSITY project BIOPOOL.

\section{References}

Adamowicz SJ, Gregory TR, Marinone MC, Hebert PDN (2002) New insights into the distribution of polyploid Daphnia: the Holarctic revisited and Argentina explored. Mol Ecol 11: 1209-1217

Adamowicz SJ, Purvis A (2005) How many branchiopod crustacean species are there? Quantifying the components of underestimation. Global Ecol Biogeogr 14: 455-478

Aguilera X, Mergeay J, Wollebrants A, Declerck S, De Meester L (2007) Asexuality and polyploidy in Daphnia from the tropical Andes. Limnol Oceanogr 52: 2079-2088

Allen D, Lynch M (2008) Both costs and benefits of sex correlate with relative frequency of asexual reproduction in cyclically parthenogenetic Daphnia pulicaria populations. Genetics 179: 1497-1502

Beaton MJ, Hebert PDN (1988) Geographical parthenogenesis and polypoidy in Daphnia pulex. Am Nat 132: 837-845

Bell, G (1982) The masterpiece of nature: the evolution and genetics of sexuality. University of California Press, Berkeley

Bierzychudek, P (1985) Patterns in plant parthenogenesis. Experientia 41: 1255-1264

Boersma M, Spaak P, De Meester L (1998) Predator-mediated plasticity in morphology, life history, and behavior of Daphnia: the uncoupling of responses. Am Nat 152: 237-248

Brendonck L, De Meester L (2003) Egg banks in freshwater zooplankton: evolutionary and ecological archives in the sediment. Hydrobiologia 491: 65-84

Cáceres CE (1998) Interspecific variation in the abundance, production, and emergence of Daphnia diapausing eggs. Ecology 79: 1699-1710

Cáceres CE, Tessier AJ (2003) How long to rest: the ecology of optimal dormancy and environmental constraint. Ecology 84: 1189-1198 
Cáceres CE, Tessier AJ (2004a) Incidence of diapause varies among populations of Daphnia pulicaria. Oecologia 141: 425-431

Cáceres CE, Tessier AJ (2004b) To sink or swim: variable diapause strategies among Daphnia species. Limnol Oceanogr 49: 1333-1340

Capaul M, Ebert D (2003) Parasite-mediated selection in experimental Daphnia magna populations. Evolution 57: 249-260

Carius HJ, Little TJ, Ebert D (2001) Genetic variation in a host-parasite association. Evolution 55: $1146-1152$

Carvalho GR (1994) Genetics of aquatic clonal organisms. In: Beaumont A (ed) Genetics and evolution of aquatic organisms. Chapman and Hall, London, pp. 291-323

Černý M, Hebert PDN (1999) Intercontinental allozyme differentiation among four holarctic Daphnia species. Limnol Oceanogr 44: 1381-1387

Cohen D, Levin SA (1987) The interaction between dispersal and dormancy strategies in varying and heterogeneous environments. Lect Notes Biomath 71: 110-122

Colbourne JK, Wilson CC, Hebert PDN (2006) The systematics of Australian Daphnia and Daphniopsis (Crustacea: Cladocera): a shared phylogenetic history transformed by habitatspecific rates of evolution. Biol J Linn Soc 89: 469-488

Cousyn C, De Meester L, Colbourne JK, Brendonck L, Verschuren D, Volckaert F (2001) Rapid, local adaptation of zooplankton behavior to changes in predation pressure in the absence of neutral genetic changes. Proc Natl Acad Sci USA 98: 6256-6260

Crease TJ, Stanton DJ, Hebert PDN (1989) Polyphyletic origins of asexuality in Daphnia pulex. II mitochondrial-DNA variation. Evolution 43: 1016-1026

Crow JF (1994) Advantages of sexual reproduction. Dev Genet 15: 205-213

Carius HJ, Little TJ, Ebert D (2001) Genetic variation in a host-parasite association: potential for coevolution and frequency-dependent selection. Evolution 55: 1146-1152.

Charlesworth, B (1990) Mutation-selection balance and the evolutionary advantage of sex and recombination. Genet Res 55: 199-221

De Meester L (1993a) Genotype, fish-mediated chemicals, and phototaxis in Daphnia magna. Ecology 74: 1467-1474

De Meester L (1993b) Inbreeding and outbreeding depression in Daphnia. Oecologia 96: 80-84

De Meester L (1996) Local genetic differentiation and adaptation in freshwater zooplankton populations: patterns and processes. Ecoscience 3: 385-399

De Meester L, Gómez A, Okamura B, Schwenk K (2002) The monopolization hypothesis and the dispersal-gene flow paradox in aquatic organisms. Acta Oecol-Intern J Ecol 23: 121-135

De Meester L, Gómez A, Simon JC (2004) Evolutionary and ecological genetics of cyclical parthenogens. In Moya A, Font E (eds) Evolution from molecules to ecosystems. Oxford University Press, Oxford, pp. 122-134

De Meester L, Vanoverbeke J (1999) An uncoupling of male and sexual egg production leads to reduced inbreeding in the cyclical parthenogen Daphnia. Proc Roy Soc Lond B 266: 2471-2477

De Meester L, Vanoverbeke J, De Gelas K, Ortells R, Spaak P (2006) Genetic structure of cyclic parthenogenetic zooplankton populations - a conceptual framework. Arch Hydrobiol 167: 217-244

DeStasio, BT (1989) The seed bank of a freshwater crustacean - copepodology for the plant ecologist. Ecology 70: 1377-1389

Decaestecker E, De Meester L, Ebert D (2002) In deep trouble: habitat selection constrained by multiple enemies. Proc Natl Acad Sci USA 91: 5481-5484

Decaestecker E, Declerck S, De Meester L, Ebert D (2005) Ecological implications of parasites in natural Daphnia magna populations. Oecologia 144: 382-390

Decaestecker E, Lefever C, De Meester L, Ebert D (2004) Haunted by the past: evidence for dormant stage banks and epibionts of Daphnia. Limnol Oceanogr 49: 1355-1364

Decaestecker E, Vergote A, Ebert D, De Meester L (2003) Evidence for strong host clone-parasite species interactions in the Daphnia-microparasite system. Evolution 57: 784-792 
Decaestecker E, Gaba S, Raeymaekers J, Stoks R, Van Kerckhoven L, Ebert D, De Meester L (2007) Host-parasite red queen dynamics archived in pond sediment. Nature 450: 870-873

Deng HW, Lynch M (1996) Change of genetic architecture in response to sex. Genetics 143: 203-212

Doncaster CP, Pound GE, Cox SJ (2000) The ecological cost of sex. Nature 404: 281-285

Duffy MA, Hall SR, Tessier AJ, Huebner M (2005) Selective predators and their parasitized prey: Are epidemics in zooplankton under top down control? Limnol Oceanogr 50: 412-420

Duffy MA, Sivars-Becker L (2007) Rapid evolution and ecological host-parasite dynamics. Ecol Lett 10: 44-53

Dufresne F, Hebert PDN (1994) Hybridization and origins of polyploidy. Proc Roy Soc Lond B 258: $141-146$

Dufresne F, Hebert PDN (1995) Polyploidy and clonal diversity in an arctic cladoceran. Heredity 75: 45-53

Dufresne F, Hebert PDN (1997) Pleistocene glaciations and polyphyletic origins of polyploidy in an arctic cladoceran. Proc Roy Soc Lond B 264: 201-206

Dufresne F, Hebert PDN (1998) Temperature-related differences in life history characteristics between diploid and polyploid clones of the Daphnia pulex complex. Ecoscience 5: 433-437

Duncan A, Mitchell SE, Little TJ (2006) Parasite-mediated selection and the role of sex and diapause in Daphnia. J Evol Biol 19: 1183-1189

Duncan A, Little TJ (2007) Parasite-driven genetic change in a natural population of Daphnia. Evolution 61: 796-803

Ebert D (1994) Virulence and local adaptation of a horizontally transmitted parasite. Science 265: $1084-1086$

Ebert D (2005) Ecology, Epidemiology, and Evolution of Parasitism in Daphnia [Internet]. Bethesda (MD): National Library of Medicine (USA), National Center for Biotechnology Information

Ebert D (2008) Host-parasite coevolution: insights from the Daphnia-parasite model system. Curr Opin Microbiol 11: 290-301

Ebert D, Haag C, Kirkpatrick M, Riek M, Hottinger JW, Pajunen VI (2002) A selective advantage to immigrant genes in a Daphnia metapopulation. Science 295: 485-488

Ebert D, Hamilton WD (1996) Sex against virulence: the coevolution of parasitic diseases. Trends Ecol Evol 11: 79-82

Felsenstein J (1974) The evolutionary advantage of recombination. Genetics 78: 737-756

Gandon S, Buckling A, Decaestecker E, Day T (2008) Host-parasite coevolution and patterns of adaptation across time and space. J Evol Biol 21: 1861-1866

Forró L, Korovchinsky NM, Kotov AA, Petrusek A (2008) Global diversity of cladocerans (Cladocera, Crustacea) in freshwater. Hydrobiologia 595: 177-184

Glesener RR, Tilman D (1978) Sexuality and the components of environmental uncertainty: clues from geographic parthenogenesis in terrestrial animals. Am Nat 112: 659-673

Gliwicz ZM, Slusarczyk A, Slusarczyk M (2001) Life history synchronization in a long-lifespan single-cohort Daphnia population in a fishless alpine lake. Oecologia 128: 368-378

Green J (1974) Parasites and epibionts of cladocera. Trans Zool Soc Lond 32: 417-515

Gregory TR, Hebert PDN (1999) The modulation of DNA content: proximate causes and ultimate consequences. Genome Res 9: 317-324

Haag CR, Ebert D (2004) Parasite-mediated selection in experimental metapopulations of Daphnia magna. Proc Roy Soc Lond B 271: 2149-2155

Haag CR, Hottinger JW, Riek M, Ebert D (2002) Strong inbreeding depression in a Daphnia metapopulation. Evolution 56: 518-526

Haag CR, Sakwinska O, Ebert D (2003) A test of a synergistic interaction between infection and inbreeding in Daphnia magna. Evolution 57: 777-783

Hairston NG (1996) Zooplankton eggs as biotic reservoirs in changing environments. Limnol Oceanogr 41: 1087-1092 
Hairston, NG, DeStasio BT (1988) Rate of evolution slowed by a dormant propagule pool. Nature 336: $239-242$

Hairston NG, Lampert W, Cáceres CE, Holtmeier CL, Weider LJ, Gaedke U, Fischer JM, Fox JA, Post DM (1999) Rapid evolution revealed by dormant eggs. Nature 401:446

Hairston NG, Holtmeier CL, Lampert W, Weider LJ, Post DM, Fischer JM, Caceres CE, Fox JA, Gaedke U (2001) Natural selection for grazer resistance to toxic Cyanobacteria: evolution of phenotypic plasticity? Evolution 55: 2203-2214

Hall SR, Tessier AJ, Duffy MA, Huebner M, Cáceres CE (2006) Warmer does not have to mean sicker: temperature and predators can jointly drive timing of epidemics. Ecology 87: $1684-1695$

Hamilton WD (1980) Sex versus non-sex versus parasites. Oikos 35: 282-290

Hamilton WD, Axelrod R, Tanese R (1990) Sexual reproduction as an adaptation to resist parasites (A review). Proc Natl Acad Sci USA 87: 3566-3573

Hebert PDN (1978) Population biology of Daphnia (Crustacea, Daphnidae). Biol Rev Cambridge Phil Soc 53: 387-426

Hebert PDN (1981) Obligate asexuality in Daphnia. Am Nat 117: 784-789

Hebert PDN (1987) Genetics of Daphnia. In: Peters RH, De Bernardi R (eds) Daphnia. Mem Inst Ital Idrobiol 45: 439-460

Hebert PDN (1995) The Daphnia of North America: an illustrated fauna (on CD-rom). Cyber Natural Software, Guelph, Ontario

Hebert PDN, Beaton MJ, Schwartz SS, Stanton DJ (1989) Polyphyletic origins of asexuality in Daphnia pulex. I. Breeding-system variation and levels of clonal diversity. Evolution 43: 1004-1015

Hebert PDN, Finston TL (2001) Macrogeographic patterns of breeding system diversity in the Daphnia pulex group from the United States and Mexico. Heredity 87: 153-161

Hebert PDN, Rowe CL, Adamowicz SJ (2007) Life at low temperatures: A novel breeding-system adjustment in a polar cladoceran. Limnol Oceanogr 52: 2507-2518

Hebert PDN, Wilson CC (1994) Provincialism in plankton - endemism and allopatric speciation in Australian Daphnia. Evolution 48: 1333-1349

Hebert PDN, Wilson CC (2000) Diversity of the genus Daphniopsis in the saline waters of Australia. Can J Zool 78: 794-808

Hedrick PW (1995) Genetic polymorphism in a temporally varying environment: effects of delayed diapause. Heredity 75: 164-170

Howard RS, Lively CM (1998) The maintenance of sex by parasitism and mutation accumulation under epistatic fitness functions. Evolution 52: 604-610

Hurst LD, Peck JR (1996) Recent advances in understanding of the evolution and maintenance of sex. Trends Ecol Evol 11: 46-52

Innes DJ (1989) Genetics of Daphnia obtusa: genetic load and linkage analysis in a cyclical parthenogen. J Hered 80: 6-10

Innes DJ, Fox CJ, Winsor GL (2000) Avoiding the cost of males in obligately asexual Daphnia pulex (Leidig). Proc Roy Soc Lond B 267: 991-997

Innes DJ, Hebert PDN (1988) The origin and genetic basis of obligate parthenogenesis in Daphnia pulex. Evolution 42: 1024-1035

Johnson PTJ, Longcore JE, Stanton DE, Carnegie RB, Shields JD, Preu ER (2006) Chytrid infections of Daphnia pulicaria: development, ecology, pathology and phylogeny of Polycarium leave. Freshw Biol 51: 634-648

Kearney M (2005) Hybridization, glaciation and geographical parthenogenesis. Trends Ecol Evol 10: 495-502

Killick SC, Carlsson AM, West SA, Little TJ (2006) Testing the pluralist approach to sex: the influence of environment on synergistic interactions between mutation load and parasitism in Daphnia magna. J Evol Biol 19: 1603-1611

King CE, Schonfeld J (2001) The approach to equilibrium of multilocus genotype diversity under clonal selection and cyclical parthenogenesis. Hydrobiologia 446: 323-331 
Kondrashov AS (1982) Selection against harmful mutations in large sexual and asexual populations. Genet Res 40: 325-332

Kondrashov AS (1988) Deleterious mutations and the evolution of sexual reproduction. Nature 336: 435-440

Korovchinsky NM (1996). How many species of Cladocera are there? Hydrobiologia 321: 191-204

Korovchinsky NM (2005). New species of Holopedium Zaddach, 1855 (Crustacea: Cladocera: Ctenopoda) from Greenland. J Limnol 64: 103-112

Lass S, Ebert D (2006) Apparent seasonality in parasite dynamics: analysis of cyclical prevalence patterns. Proc Roy Soc Lond B 273: 109-206

Lewis WM (1987) The cost of sex. In Stearns SC (ed), The evolution of sex and its consequences. Birkhäuser Verlag, Basel, p. 33-57

Limburg PA, Weider LJ (2002) 'Ancient' DNA in the resting egg bank of a microcrustacean can serve as a palaeolimnological database. Proc Roy Soc Lond B 269: 281-287

Little TJ, Demelo R, Taylor DJ, Hebert PDN (1997) Genetic characterization of an arctic zooplankter: insights into geographic polyploidy. Proc Roy Soc Lond B 264: 1363-1370

Little TJ, Ebert D (1999). Associations between parasitism and host genotype in natural populations of Daphnia (Crustacea: Cladocera). J Anim Ecol 67: 134-149

Little TJ, Ebert D (2001) Temporal patterns of genetic variation for resistance and infectivity in a Daphnia-microparasite system. Evolution 55: 1146-1152

Lynch M (1984) Destabilizing hybridization, general purpose genotypes and geographic parthenogenesis. Quart Rev Biol 59: 257-290

Lynch M, Deng HW (1994) Genetic slippage in response to sex. Am Nat 144: 242-261

Lynch M, Gabriel W (1983) Phenotypic evolution and parthenogenesis. Am Nat 122: 745-764

Maynard Smith J (1971) The origin and maintenance of sex. In Williams GC (ed) Group selection. Aldine-Atherton, Chicago

Maynard Smith, J (1978) The evolution of sex. Cambridge University Press, Cambridge, UK

Maynard Smith J (1989) Evolutionary genetics. Oxford University Press, Oxford

Mergeay J, Verschuren D, De Meester L (2006) Invasion of an asexual American water flea clone throughout Africa, and rapid displacement of a native sibling species. Proc Roy Soc Lond B 273: 2839-2944

Mergeay J, Vanoverbeke J, Verschuren D, De Meester L (2007) Extinction, recolonisation and dispersal through time in a planktonic crustacean. Ecology 88: 3032-3043

Mergeay J, Aguilera X, Declerck S, Petrusek A, Huyse T, De Meester L (2008) The genetic legacy of polyploid Bolivian Daphnia: the tropical Andes as a source for the North and South American D. pulicaria complex. Mol Ecol 17: 1789-1800

Mitchell SE, Read AF, Little TJ (2004) The effect of a pathogen epidemic on the genetic structure and reproductive strategy of the crustacean Daphnia magna. Ecol Lett 7: 848-858

Mitchell SE, Rogers ES, Little TJ, Read AF (2005) Host-parasite and genotype-by-environment interactions: temperature modifies potential for selection by a sterilizing pathogen. Evolution 59: $70-80$

Muller HJ (1932) Some genetic aspects of sex. Am Nat 66: 118-138

Omilian AR., Cristescu MEA, Dudycha JL, Lynch M (2006) Ameiotic recombination in asexual lineages of Daphnia. Proc Natl Acad Sci USA 103: 18638-18643

Ortells R, Gomez A, Serra M (2006) Effects of duration of the planktonic phase on rotifer genetic diversity. Arch Hydrobiol 167: 203-216

Otto SP, Whitton J (2000) Polyploid incidence and evolution. Annu Rev Genet 34: 401-437

Paland S, Colbourne J, Lynch M (2005) Evolutionary history of contagious asexuality in Daphnia pulex. Evolution 59: 800-813

Paland S, Lynch M (2006) Transitions to asexuality result in excess amino acid substitutions. Science 311: 990-992

Peck JR (1994) A ruby in the rubbish - beneficial mutations, deleterious mutations and the evolution of sex. Genetics 137: 597-606

Peck JR, Waxman D (2000) Mutation and sex in a competitive world. Nature 406: 399-404 
Pérez-Martínez C, Barea-Arco J, Conde-Porcuna JM, Morales-Baquero R (2007) Reproduction strategies of Daphnia pulicaria population in a high mountain lake of Southern Spain. Hydrobiologia 594: 75-82

Pfrender M, Lynch M (2000) Quantitative genetic variation in Daphnia: temporal changes in genetic architecture. Evolution 54: 1502-1509

Pijanowska J, Stolpe G (1996) Summer diapause in Daphnia as a reaction to the presence of fish. J Plankton Res 18: 1407-1412

Pound GE, Doncaster CP, Cox SJ (2002) A Lotka-Volterra model of coexistence between a sexual population and multiple asexual clones. J Theor Biol 217: 535-545

Pound GE, Cox SJ, Doncaster CP (2004) The accumulation of deleterious mutations within the frozen niche variation hypothesis. J Evol Biol 17: 651-662

Refardt D, Ebert D (2007) Inference of parasite local adaptation using two different fitness components. J Evol Biol 20: 921-929

Schultz TW (1977) Fine structure of the ephippium of Daphnia pulex (Crustacea: Cladocera). Trans Am Microsc Soc 96: 313-321

Schwartz SS, Hebert PDN (1987) Breeding system of Daphniopsis ephemeralis: adaptations to a transient environment. Hydrobiologia 145: 195-200

Schwenk K, Spaak P (1995) Evolutionary and ecological consequences of interspecific hybridization in cladocerans. Cell Mol Life Sci 51: 465-481

Simon JC, Delmotte F, Rispe C, Crease T (2003) Phylogenetic relationships between parthenogens and their sexual relatives: the possible routes to parthenogenesis in animals. Biol J Linn Soc 79: $151-163$

Sluzarczyk M (1995) Predator-induced diapause in Daphnia. Ecology 76: 1008-1013

Spitze K (1992) Predator mediated plasticity of prey life history and morphology: Chaoborus americanus predation on Daphnia pulex. Am Nat 139: 229-247

Stearns SC (1987) The evolution of sex and its consequences. Birkhäuser Verlag, Basel

Stirnadel HA, Ebert D (1997) Prevalence, host specificity and impact on host fecundity of microparasites and epibionts in three sympatric Daphnia species. J Anim Ecol 66: 212-222

Taylor DJ, Crease TJ, Brown WM (1999) Phylogenetic evidence for a single long-lived clade of crustacean cyclic parthenogens and its implications for the evolution of sex. Proc Roy Soc Lond B 266: 791-797

Templeton AR, Levin DA (1979) Evolutionary consequences of seed pools. Am Nat 114: 232-249

Tessier AJ, Young A, Leibold M (1992) Population dynamics and body-size selection in Daphnia. Limnol Oceanogr 37: 1-13

Tollrian R, Harvell CD (1999) The ecology and evolution of inducible defenses. Princeton University Press, Princeton

Vale PF, Stjernman M, Little TJ (2008) Temperature dependent costs of parasitism and the maintenance of polymorphism under genotype by environment interactions. J Evol Biol 21: $1418-1427$

Vanoverbeke J, De Meester L (1997) Among-populational genetic differentiation in the cyclical parthenogen Daphnia magna (Crustacea, Anomopoda) and its relation to geographic distance and clonal diversity. Hydrobiologia 360: 135-142

Van Valen L (1973) A new evolutionary law. Evol Theory 1: 1-30

Vrijenhoek RC (1979) Factors affecting clonal diversity and coexistence. Am Zool 19: 787-797

Weider LJ, Hobaek A, Hebert PDN, Crease TJ (1999) Holarctic phylogeography of an asexual species complex - II. Allozymic variation and clonal structure in Arctic Daphnia. Mol Ecol 8: $1-13$

West SA, Lively CM, Read AF (1999) A pluralist approach to sex and recombination. J Evol Biol 12: $1003-1012$

Whitlock, MC, Ingvarsson PK, Hatfield T (2000) Local drift load and the heterosis of interconnected populations. Heredity $84: 452-457$

Wolinska J, Bittner K, Ebert D, Spaak P (2006) The coexistence of hybrid and parental Daphnia: the role of parasites. Proc Roy Soc Lond B 273: 1977-1983 
Woolhouse MEJ, Webster JP, Domingo E, Charlesworth B, Levin BR (2002) Biological and biomedical implications of the co-evolution of pathogens and their hosts. Nature Genet 32: 569-577

Zaffagnini F (1987) Reproduction in Daphnia. In Peters RH, De Bernardi R (eds) Daphnia. Mem Inst Ital Idrobiol 45: 245-284

Zakharov, IA, Suslova NG, Fedorova IV (1970) Polyploidy and radioresistance in yeast. I. The effects of mutation on radioresistance of polyploid strains of Saccharomyces cerevisiae (in Russian). Genetika 6: 100-106

Zbinden M, Haag CR, Ebert D (2008) Experimental evolution of Daphnia magna populations in response to parasite treatment. J Evol Biol 21: 1068-1078 